\title{
Teaching Search Techniques on the Computerized Catalog and on the Traditional Card Catalog: A Comparative Study
}

\section{Opritsa D. Popa, Deborah A. Metzger, and James A. Singleton}

Libraries establishing online catalogs often retain their card catalogs until complete retroactive online conversion can be achieved; consequently, bibliographic instruction (BI) librarians teach search strategies on both systems. This study measures students' grasp of library concepts taught on- and offline and preferences for one system over the other. Results show that students prefer the online catalog. When students are taught search strategies online first, followed by lectures on the card catalog, their test scores increase more than for those taught in the reverse order. Performance and preference are similar in American and international students. If incorporated in BI programs, these findings will improve teaching effectiveness.

As in numerous libraries across the nation, at the University of California-Davis Shields Library, the Melvyl online catalog coexists with the traditional card catalog. Both catalogs will be maintained for many years until a complete online conversion occurs. Most students find the online card catalog an attractive library feature. Online catalog user studies indicate that regardless of the degree of knowledge in using the computerized catalog, students overwhelmingly prefer this system to the manual card catalog. ${ }^{1}$ Of those who try the online catalog "almost all change over to use it more often than the card catalog. ${ }^{\prime 2}$
Furthermore, for reasons that are not yet apparent, "OPAC (Online Public Access Catalog) users visit the library more frequently than do OPAC nonusers. ${ }^{\prime 3}$

In contrast, the library literature abounds with recriminations regarding the difficulties in using and teaching the traditional card catalog. It has been called "complicated, " "'esoteric, ", the "greatest obstacle of library research for all but the most experienced patrons," and has even been branded " $3 \times 5$ and full of holes."

Because of the problems associated with using the card catalog, bibliographic instruction (BI) librarians have had difficulty motivating students to learn systematic search techniques. The reason is simple: the majority of students does not demand comprehensiveness or precision from the card catalog. Familiar with its setup and comfortable using it, students believe that they are fairly successful in their searching. This belief is reinforced when they find at least some useful references. ${ }^{6}$ Any attempt to expand this superficial knowledge by teaching tracings, subject headings, cross-references, and filing rules is met with a complete lack of interest.

At Shields Library the main card catalog is a union catalog for the University of California-Davis main library and its branches. It is divided into author/title and subject catalogs with access points by

Opritsa D. Popa is Associate Librarian and Deborah A. Metzger is Associate Librarian at the Shields Library, University of California, Davis, California 95616. James A. Singleton is Staff Research Associate at the Laboratory for Energy-Related Health Research, University of California, Davis, California 95616. This research was supported by a grant from the Librarians Association of the University of California-Davis. Irene Hoffman's input during the initial stages of the study is gratefully acknowledged. 
personal and corporate author, title, subject (LC authorized subject headings), and series title. Main entries display full bibliographic information with call number and location. Periodicals are accessible not only through the card catalog, but also by using a periodicals list on microfiche or a separate periodicals database, the California Academic Libraries List of Serials (CALLS), loaded into the online catalog.

The UC Melvyl online catalog has been available since 1981 . It primarily contains records for the holdings of the nine University of California campus libraries. As of October 1987 the catalog featured approximately $6,500,000$ records; of these 787,000 belong to the Davis campus. CALLS was added online in 1984 . The Melvyl online catalog functions in parallel with the main card catalog. It complements the latter by being more current: records are entered online months before cards are filed in the main card catalog. Melvyl is available for patron use whenever the library is open, or it can be accessed at any time by an outside personal computer and modem. Several library terminals have printers attached. Points of access parallel those of the card catalog and feature personal and corporate author, title, LC subject headings, and series title. Additionally Melvyl permits access by subtitle, title keywords, and series keywords. Records can be displayed in a review format (author, fraction of title, and year of publication), an abbreviated format (bibliographic entry, call number, and campus location), or a long format (complete bibliographic record). As previously mentioned, periodical titles in complete or abbreviated form may be searched in the separate periodicals file. The online catalog is "user-friendly," allowing a menusearch approach as well as a more flexible, rapid command mode for experienced searchers.

Because the card catalog offers full retrospective coverage but lacks currency, while the Melvyl catalog (as of this date) offers currency without complete retrospective coverage, at times it is necessary to use both catalogs. This situation has prompted us to test the following hypotheses:
1. Similar search concepts can be taught on the Melvyl online catalog and on the traditional card catalog.

Since the online catalog features the same access points as the card catalogauthor, corporate author, title, subject, series, periodical titles-it can accommodate search techniques traditionally taught on the card catalog. Furthermore, the "long display" lists the same elements as the main entry on a catalog card, allowing BI librarians to show and explain online such fields as title/authorship statement, edition, imprint, collation, series, notes, tracings, and call number. The first hypothesis is critical to the study as all following hypotheses are dependent upon the demonstration that search concepts can be taught by using the online catalog.

If the first hypothesis is true, then the potential advantage of teaching on the online catalog versus the card catalog needs to be demonstrated:

2. Teaching search concepts online is more effective than teaching the same concepts using the card catalog.

Once the online catalog has been established as an effective bibliographic instruction tool, the sequence in which the two systems are taught needs to be studied:

3. The sequence in which the two systems are taught plays a role in how well the concepts are understood.

The student population of the University of California-Davis is made up of international as well as American students. The fourth hypothesis compares the results of bibliographic instruction for these two groups:

4. Conceptual understanding and preference of one system over the other are similar in American and international students.

We also considered some general questions about both catalogs and their use:

After being exposed to both online and traditional card catalog searching, if the students are free to choose, which method will they prefer? Are usage, time spent on a system, and correct answers related? Which concepts are the most difficult to understand? 


\section{METHODOLOGY AND DESIGN}

\section{Subjects}

The subjects were selected from the UCDavis student body according to the following criteria: they had to be incoming students with no formal library training or experience with an online catalog and be willing to participate. American students were contacted at the first meeting of an introductory library credit course while international students were recruited at the annual introductory library lecture offered during their fall orientation week. Both the American and international students were invited to register for one of two sessions teaching library skills. Although 30 American and 30 international students registered for the sessions, only 29 American and 22 international students actually attended.

As much as we wanted to recruit subjects representative of these two student populations, the constraints of using library "illiterate" students limited our choice to those willing to take the library training. Therefore both the American and international students were part of a select rather than random group.

\section{Study Design}

A cross-over design with a baseline (pretest) and a posttest was used for the study (see figure 1). The pretest sought to determine the initial level of the students' knowledge. After the pretest, the American and international students were separated into two subgroups. The students who registered for the first session were assigned to the subgroup that was taught search techniques in the card catalog and then online, while the students who registered for the second session were taught in the reverse order. Because some students who had registered failed to attend the sessions, the subgroups had uneven numbers of participants.

Each subgroup was taught search strategies using either the card catalog (Off subgroup with 13 American and 6 international students) or Melvyl (On subgroup with 16 American and 16 international students). This first level of teaching consisted of a lecture and practice exercise fol- lowed by a test. A second level of teaching followed with the groups "crossing over": the On subgroup that had been exposed to searching on Melvyl was taught searching in the card catalog while the Off subgroup, which first learned to use the card catalog, was instructed in the use of the online catalog. A second test concluded this stage of teaching. A posttest was then given to both On and Off groups allowing students to apply their newly acquired search knowledge by using the system of their choice. Finally, an opinion survey gave students an opportunity to express their views about searching in the card catalog versus searching in the online catalog.

Unlike a single group linear design, the cross-over design permits valid intergroup comparisons. ${ }^{7}$ It offers the possibility of comparing test results of On and Off subgroups on the same level of teaching; it permits the analysis of whether teaching online first, followed by offline, facilitates the understanding of concepts. This design also allows a comparison of On and Off subgroups in the preference for one system over another.

\section{Methods of Teaching}

The study was conducted in the first week of the fall quarter before students started using Shields Library. For both the online and card catalog lectures, identical teaching tools and lecture outlines were used. A slide presentation and a discussion covered the following topics:

- Definition of the catalog

- Coverage (types of publications and publication dates)

- Access points

- Record information (based on main entry in the card catalog and the long display on Melvyl)

- Interpreting and locating material by call number

- Filing rules (importance in the card cata$\log$ versus online)

The session concluded with practical searching exercises in the card catalog and on the Melvyl catalog. A test consisting of simple and multiple-choice questions followed. The tests included comparable 


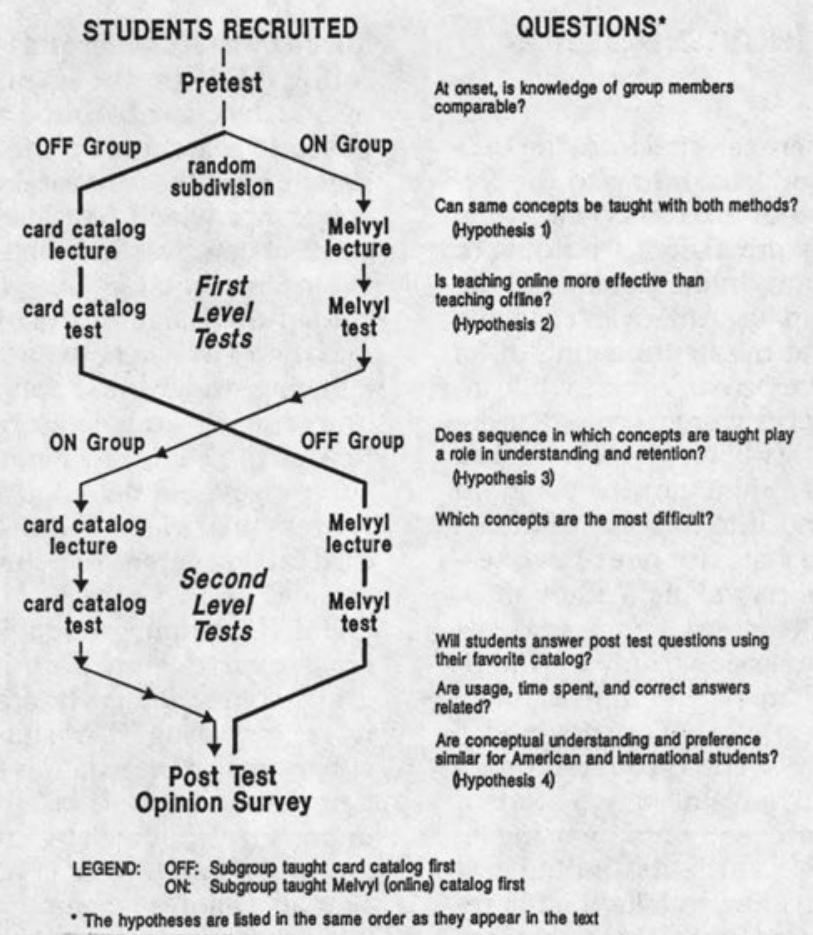

FIGURE 1

Cross-Over Study Flowchart

questions relating to the seven key concepts (author, corporate author, title, subject, LC subject headings, series title, and periodicals). Lectures and tests for each group were completed within a single four-and-one-half-hour session. The coded test results were statistically analyzed using Minitab Version 5.

\section{STATISTICAL ANALYSIS}

Descriptive statistical methods included the calculation of mean, standard deviation, and when required by comparison of groups, a 95\% confidence interval. At each step, overall test scores for each student (expressed as a percentage of items answered correctly) as well as key concept scores (percentage of students in a group answering correctly) on author, corporate author, title, series title, subject, LC subject headings, and periodicals were recorded.
At every stage of the analysis, the distribution of the data was assessed to determine the appropriate statistical method. If the distribution seemed normal, the t-test or ANOVA was applied. If the distribution was skewed or irregular, nonparametric methods that relax the assumptions to either symmetric distributions (i.e., Mann-Whitney, Wilcoxin) or no restrictions (sign-procedures) were selected. ${ }^{8}$ Proportions of students with correct responses were evaluated with $95 \%$ confidence intervals, based on the binomial distribution. ${ }^{9}$ Improvements in proportions were also evaluated with the binomial distribution. ${ }^{10}$ The pretest (baseline) scores were used: (1) to compare library skills at the beginning of the study; (2) to provide a reference level for change in knowledge; and (3) to decrease the bias due to differing amounts of knowledge. 


\section{RESULTS}

Pretest Analysis: Determining the amount of library knowledge at the baseline.

The initial level of library skills assessed by pretest scores (see figure 2 ) was similar in American and international students in both the On and Off subgroups. Confidence intervals $(73 \%$ to $79 \%$ ) for median pretest score based on the sign test all overlapped.

Hypothesis 1: Similar search concepts can be taught using both the online cata$\log$ and the card catalog.

This hypothesis was analyzed by comparing the results of the pretest and the level-one test. For concepts, the improvement from the pretest was expressed as $\left(p_{2}-p_{1}\right)=(b-c) / n$ where $n=a+b+$ $c+d ; p_{1}$ and $p_{2}$ are the proportion of students answering correctly on the pretest and first-level test, respectively; $a$ is the number of subjects in the group answering correctly on both the pretest and first-
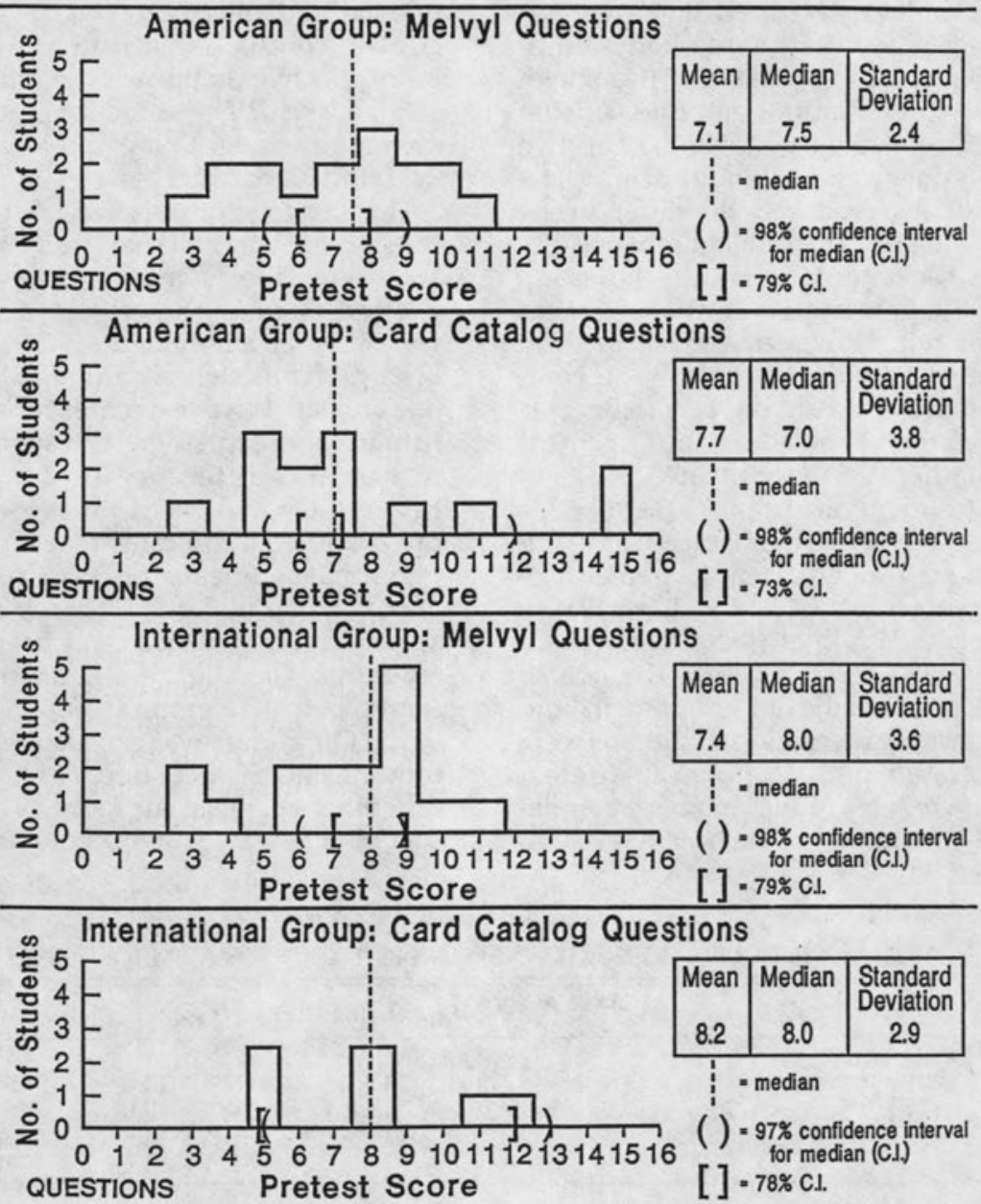

FIGURE 2

The Initial Level of Library Skills Assessed by Pretest Scores 
level test; $b$ is the number of subjects in the group improving from the pretest; $c$ is the number of subjects in the group who answered correctly on the pretest but not on the first-level test; and $d$ is the number of students who were incorrect in both tests. In the sign test that was used a significant improvement is indicated by improvements from wrong on the pretest to correct on the first-level test occurring in more than $50 \%$ of the subjects that changed responses for pretest to first-level test. ${ }^{11}$

We found that compared to the pretest, at the first-level test both the American and international students had significantly higher scores (see table 1), and with an exception for author and title, a better grasp of concepts (see table 2). The two concepts on which no significant improvement was observed were the easier onesauthor and title. The small number of subjects in the international Off subgroup makes the assessment of their changes very difficult. However, when American and international students were combined across study groups, all concepts except author showed an improvement $(p<.05)$; there was a small but nonsignificant betterment on author $(10 \%: b=8, c$ $=3, p=.11)$. For other concepts the improvement ranged from 43 percentage points (subject: $b=23, c=1, p<.05$ ) to 72 percentage points (LC subject headings: $b=37, c=0, \mathrm{p}<.05)$. The overall first test scores of the On subgroup in both American and international students were uncorrelated with the overall pretest scores (Pearson product-moment correlation $r=.14$ to $.35, p>.05)$. However, in the international Off subgroup, the higher the initial score, the higher the level-one test score $(r=.80, .05<p<.10)$.

Hypothesis 2: Teaching search strategies using the online catalog is more effective than teaching search strategies on the card catalog.

This hypothesis was evaluated by comparing the improvement between the pretest and the level-one test in the American and international On and Off subgroups. As shown in tables 1 and 2 there was a large spread of values around fairly similar means yielding wide, overlapping confidence intervals. Thus evidence is insufficient to conclude that teaching online is more effective than teaching offline.

Hypothesis 3: The sequence in which the systems are taught plays a role in the understanding of concepts.

This third hypothesis was addressed by cross-over analysis of the first- and second-level tests and by analysis of the posttest results. The cross-over analysis was based on a modified ANOVA model. Briefly, it consisted of summing the levelone and level-two test scores for each participant and expressing the sequence effect as the difference in mean sums between On and Off groups (see Appen$\operatorname{dix}$ A). Table 3 indicates that the level of performance (means of correct answers) was very similar for either method of search in both American and international students. The slightly higher mean observed in the On groups compared to that of the Off groups was not statistically significant since $95 \%$ confidence intervals for differences in mean sums covered 0 . Thus there is a tendency favoring online teach-

TABLE 1

OVERALL PERCENT CORRECT ANSWERS IN THE TESTS ADMINISTERED

\begin{tabular}{lcccc}
\hline \hline Test/Group & On & American Group & \multicolumn{2}{c}{ International Group } \\
& \multicolumn{1}{c}{ Off } & On \\
\hline Number of subjects & 16 & 13 & 16 & 6 \\
Pretest & $44.5 \pm 15.1$ & $48.5 \pm 23.5$ & $46.0 \pm 15.1$ & $51.0 \pm 18.2$ \\
Level 1 & $75.5 \pm 9.8$ & $79.2 \pm 6.6$ & $74.7 \pm 12.0$ & $65.6 \pm 18.7$ \\
Level 2 & $83.3 \pm 4.6$ & $72.9 \pm 12.9$ & $81.8 \pm 14.5$ & $76.8 \pm 14.0$ \\
Posttest & $85.1 \pm 16.5$ & $79.8 \pm 22.5$ & $83.5 \pm 18.1$ & $70.8 \pm 24.6$ \\
\hline
\end{tabular}

Legend: On = group taught online searching first. Off = group taught manual card catalog first. The numbers corresponding to the different tests administered represent mean and standard deviation of percent correct answers.

Explanation: When level 1, level 2, or posttest are compared to pretest, $p$ is less than .05 paired $t$-test for either group, regardless of teaching method (On or Off). When level 1, level 2, or posttest are compared among themselves, $p$ is larger than . 05 paired $t$-test for either group taught (On or Off). When American and international groups are compared, $p$ is larger than .05 (two-sample $t$-test). 
ing, though it is too small to be supported by statistical analysis.

The sequence effect on concepts taught is presented in table 4 . For each concept we calculated the percentage of the total number of students who gave correct answers on both the first- and second-level tests (left column, table 4). The advantage of teaching On first versus Off first (right column, table 4) was assessed for each concept by calculating the difference in the correct answers between On and Off groups: the larger the difference, the more convincing the advantage of the On group. However, since the number of students responding correctly on both tests was rather small, ranging from 6 for $\mathrm{CA}$ (corporate author) in the Off group to 30 for AU (author) in the On group (data not shown), no statistical analysis was performed. Thus table 4 indicates a variable advantage in teaching the concepts online first. The difficult concepts (i.e., those with the lowest percentage of correct answers) seem to have benefited the most from exposure first to online teaching (concepts CA, PE, LC). The easy concepts (SE, TI, AU) show the least benefit.

Hypothesis 4: Conceptual understanding and preference were similar in American and international students.

In general, there appears to be no real differences between international $O n$ and American On subgroups (table 1, $p<.05$; figure 3 ). The international On subgroup was the predominant user of the card catalog for posttest questions; however, compared to the other subgroup, this neither hampered nor improved their performance. Additionally, the American and international On subgroups performed at comparable levels in the pretest and in the opinion survey and displayed a similar sequence effect.

The international Off subgroup was two to three times smaller than all other

TABLE 2

IMPROVEMENT FROM PRETEST TO FIRST TEST BY CONCEPT

\begin{tabular}{|c|c|c|c|c|c|c|c|c|c|}
\hline \multirow[b]{2}{*}{ Number of Students } & \multicolumn{2}{|c|}{ American } & \multicolumn{2}{|c|}{ International } & \multicolumn{2}{|c|}{ All Subjects } & \multirow{2}{*}{$\begin{array}{l}\text { All } \\
\text { Am. } \\
29\end{array}$} & \multirow{2}{*}{$\begin{array}{l}\text { All } \\
\text { Intl. } \\
22\end{array}$} & \multirow[b]{2}{*}{$\begin{array}{c}\text { Overall } \\
51\end{array}$} \\
\hline & $\begin{array}{l}\text { On } \\
16\end{array}$ & $\begin{array}{l}\text { Off } \\
13\end{array}$ & $\begin{array}{l}\text { On } \\
16\end{array}$ & $\begin{array}{c}\text { Off } \\
6\end{array}$ & $\begin{array}{l}\text { On } \\
32\end{array}$ & $\begin{array}{l}\text { Off } \\
19\end{array}$ & & & \\
\hline \multicolumn{10}{|l|}{ Author } \\
\hline Improvement (\%) & $0 \%$ & 15 & 25 & -17 & 13 & 5 & 7 & 14 & 10 \\
\hline no. improving $(b)$ & 1 & 2 & 4 & 1 & 5 & 3 & 3 & 5 & 8 \\
\hline no. declining $(c)$ & 1 & 0 & 0 & 2 & 1 & 2 & 1 & 2 & 3 \\
\hline no. not changing $(a+d)$ & 14 & 11 & 12 & 3 & 26 & 14 & 25 & $1 \overline{15}$ & 40 \\
\hline \multicolumn{10}{|l|}{ LC Subject Headings } \\
\hline Improvement $(\%)$ & $88 \%$ & 77 & 62 & 50 & 75 & 68 & 83 & 59 & 72 \\
\hline no. improving $(b)$ & 14 & 10 & 10 & 3 & 24 & 13 & 24 & 13 & 37 \\
\hline no. declining $(c)$ & 0 & 0 & 0 & 0 & 0 & 0 & 0 & 0 & 0 \\
\hline no. not changing $(a+d)$ & 2 & 3 & 6 & 3 & 8 & 6 & 5 & 9 & 14 \\
\hline \multicolumn{10}{|l|}{ Title } \\
\hline Improvement (\%) & $32 \%$ & 23 & 0 & 0 & 15 & 16 & 27 & 0 & 15 \\
\hline no. improving (b) & 6 & 3 & 2 & 1 & 8 & 4 & 9 & 3 & 12 \\
\hline no. declining $(c)$ & 1 & 0 & 2 & 1 & 3 & 1 & 1 & 3 & 4 \\
\hline no. not changing $(a+d)$ & 9 & 10 & 12 & 4 & 21 & 14 & 19 & 16 & 35 \\
\hline \multicolumn{10}{|l|}{ Periodical } \\
\hline Improvement (\%) & $81 \%$ & 54 & 81 & 0 & 81 & 37 & 69 & 59 & 64 \\
\hline no. improving $(b)$ & 13 & 7 & 13 & 1 & 26 & 8 & 20 & 14 & 34 \\
\hline no. declining $(c)$ & 0 & 0 & 0 & 1 & 0 & 1 & 0 & 1 & 1 \\
\hline no. not changing $(a+d)$ & 3 & 6 & 3 & 4 & 6 & 10 & 9 & 7 & 16 \\
\hline \multicolumn{10}{|l|}{ Subject } \\
\hline Improvement (\%) & $43 \%$ & 54 & 50 & 0 & 46 & 37 & 49 & 37 & 43 \\
\hline no. improving (b) & 8 & 7 & 8 & 0 & 16 & 7 & 15 & 8 & 23 \\
\hline no. declining $(c)$ & 1 & 0 & 0 & 0 & 1 & 0 & 1 & 0 & 1 \\
\hline no. not changing $(a+d)$ & 7 & 6 & 8 & 6 & 15 & 12 & 13 & 14 & 27 \\
\hline
\end{tabular}

Legend: On $=$ Group taught online searching first. Off $=$ Group taught manual card catalog first. No. $=$ Number of students. Improvement $(\%)=\left(p_{2}-p_{1}\right)$ where $p_{1}$ and $p_{2}$ are the proportion of students answering correctly on the pretest and first-level test, respectively.

Explanation: Improvements are statistically significant for LC subject headings, periodical, and subject concepts in all groups except international Off $(p<.05)$. Statistical significance was evaluated by comparing proportions $\frac{b}{b+c}$ to .5 using the binomial distribution (sign test). 
TABLE 3

SEQUENCE EFFECT OF TEACHING

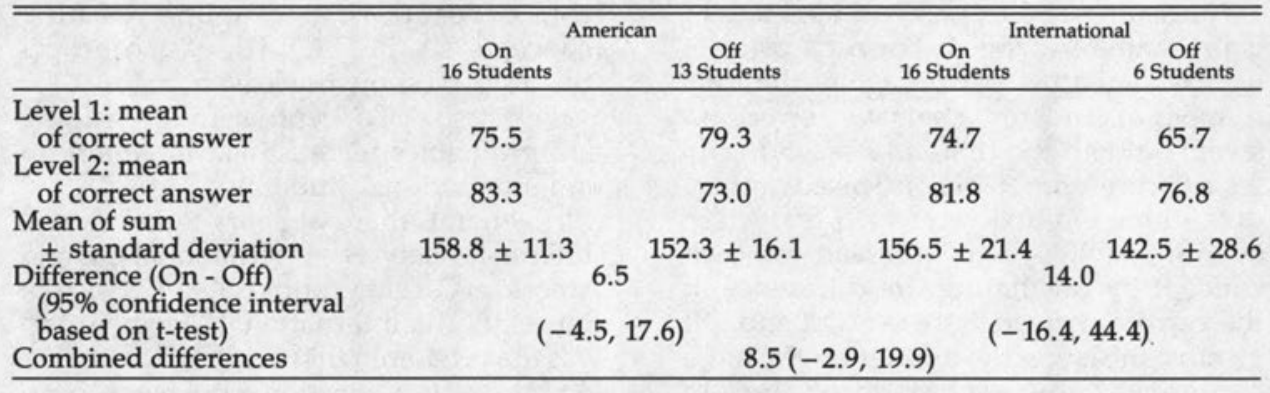

Explanation: Although the means obtained by students taught online first are higher than the means of students taught on the card catalog first, the differences are not statistically significant.

TABLE 4

SEQUENCE EFFECT ON CONCEPTS TAUGHT: COMPARISON OF STUDENTS' CORRECT ANSWERS AT THE FIRST AND SECOND TEST*

\begin{tabular}{|c|c|c|}
\hline Concept & $\begin{array}{l}\% \text { of Students with } \\
\text { Correct Answers on } \\
\text { Both Tests Overall }\end{array}$ & $\begin{array}{c}\text { Difference Between } \\
\text { On and Off Groups } \\
\text { (\% On-\% Off Students } \\
\text { American and International } \\
\text { Combined) }\end{array}$ \\
\hline $\begin{array}{l}\text { CA-Corporate author } \\
\text { PE -Periodical } \\
\text { LC -LC Subject headings } \\
\text { SE - Series } \\
\text { SU-Subject } \\
\text { TI -Title } \\
\text { AU-Author }\end{array}$ & $\begin{array}{l}51 \\
72 \\
72 \\
74 \\
76 \\
82 \\
92\end{array}$ & $\begin{array}{r}30 \\
23 \\
23 \\
1 \\
13 \\
5 \\
5\end{array}$ \\
\hline
\end{tabular}

Legend: On $=$ Group taught online first. Off $=$ Group taught card catalog first.

*Percentages of total number of students in the group answering correctly on both tests.

groups and therefore displayed the largest variability. With such a small sample size, one or two people may have a large impact on the group's summary statistics.

\section{GENERAL OBSERVATIONS CONCERNING THE CATALOGS AND THEIR USE}

\section{Students' Favored Method}

Out of 51 students, only 3 (all in the international On subgroup) preferred the card catalog; these 3 also answered most of the posttest questions by using the card catalog. Thus for all groups usage was related to preference with all but 3 students preferring and using the Melvyl catalog.

\section{Time versus Correct Answer}

Regardless of concept and group (American or international), most questions were reported as answered within $5 \mathrm{~min}$ utes ( $93 \%$ of posttest questions). Out of the 51 subjects, those taking 6 or more minutes to answer a question ranged from one (author and corporate author concepts) to 12 (subject concept). For 5 of the 7 concepts the percent of correct answers was higher for those taking 0-5 minutes to answer than for those taking 6 minutes or longer, i.e., LC subject headings ( $87 \%$ versus $50 \%, p>.05)$, title ( $86 \%$ versus $50 \%$, $p>.05)$, subject $(62 \%$ versus $42 \%, p>$ $.05)$, corporate author ( $86 \%$ versus $0 \%, p$ $>.05)$, and series $(87 \%$ versus $75 \%, p>$ $.05)$. This suggests that the longer it took to answer a question, the less likely the answer was correct, although the observed differences may have arisen by chance.

\section{Difficulty of Concepts}

Within and between groups (On and 


\begin{tabular}{|c|c|c|c|c|c|c|c|c|c|c|}
\hline \multirow{6}{*}{ Author } & & \multicolumn{2}{|c|}{ American } & \multicolumn{2}{|c|}{$\ln n$} & \multicolumn{2}{|c|}{ All Subjects } & \multirow{2}{*}{$\begin{array}{c}\text { All } \\
\text { Alm. }\end{array}$} & All & Overall \\
\hline & no. & $\begin{array}{l}\text { ON } \\
16\end{array}$ & $\begin{array}{l}\text { OFF } \\
13\end{array}$ & $\begin{array}{l}\text { ON } \\
16\end{array}$ & $\begin{array}{c}\text { OFF } \\
6\end{array}$ & $\begin{array}{l}\text { ON } \\
32\end{array}$ & $\begin{array}{l}\text { OFF } \\
19\end{array}$ & & $\begin{array}{c}\text { IntI } \\
22\end{array}$ & 51 \\
\hline & Pretest & 94 & 85 & 75 & 83 & 84 & 84 & 90 & 77 & 84 \\
\hline & First Test & 94 & 100 & 100 & 67 & 97 & 89 & 97 & 91 & 94 \\
\hline & Second Test & 100 & 100 & 94 & 100 & 97 & 100 & 100 & 95 & 98 \\
\hline & Post-Test & 94 & 100 & 100 & 100 & 97 & 100 & 97 & 100 & 98 \\
\hline Library of & Pretest & 0 & 15 & 13 & 33 & 6 & 21 & 7 & 18 & 12 \\
\hline Congress & First Test & 88 & 92 & 75 & 23 & 81 & 89 & 90 & 77 & 84 \\
\hline Subject & Second Test & 100 & 61 & 100 & 83 & 100 & 68 & 83 & 95 & 88 \\
\hline Headings & Post-Test & 88 & 61 & 94 & 67 & 91 & 63 & 76 & 86 & 80 \\
\hline Title & Pretest & 56 & 77 & 81 & 83 & 69 & 79 & 66 & 82 & 73 \\
\hline & First Test & 88 & 100 & 81 & 83 & 84 & 95 & 93 & 82 & 88 \\
\hline & Second Test & 100 & 77 & 100 & 100 & 100 & 84 & 90 & 100 & 94 \\
\hline & Post-Test & 81 & 77 & 94 & 83 & 88 & 79 & 79 & 91 & 84 \\
\hline Periodical & Pretest & 13 & 31 & 19 & 17 & 16 & 26 & 21 & 18 & 20 \\
\hline & First Test & 94 & 85 & 100 & 17 & 97 & 63 & 90 & 77 & 84 \\
\hline & Second Test & 81 & 92 & 88 & 100 & 84 & 95 & 86 & 91 & 88 \\
\hline & Post-Test & 88 & 85 & 100 & 83 & 94 & 84 & 86 & 95 & 90 \\
\hline Subject & Pretest & 38 & 31 & 38 & 67 & 38 & 42 & 34 & 45 & 39 \\
\hline & First Test & 81 & 85 & 88 & 67 & 84 & 79 & 83 & 82 & 82 \\
\hline & Second Test & 100 & 92 & 94 & 83 & 97 & 89 & 97 & 91 & 94 \\
\hline & Post-Test & 75 & 62 & 50 & 17 & 63 & 47 & 69 & 41 & 57 \\
\hline Corporate & Pretest & - & - & - & - & - & - & - & - & - \\
\hline Author & First Test & 56 & 77 & 94 & 50 & 75 & 68 & 66 & 82 & 73 \\
\hline & Second Test & 94 & 54 & 75 & 83 & 84 & 63 & 76 & 77 & 76 \\
\hline & Post-Test & 94 & 77 & 81 & 83 & 88 & 79 & 86 & 82 & 84 \\
\hline Series & Pretest & $\overline{-}$ & $\overline{-}$ & - & $\overline{-1}+1+3$ & - & $\overline{-}$ & - & $\bar{z}+1$ & $\bar{x}$ \\
\hline & First Test & 81 & 100 & 81 & 67 & 81 & 89 & 90 & 77 & 84 \\
\hline & Second Test & 94 & 77 & 94 & 100 & 94 & 84 & 86 & 95 & 90 \\
\hline & Post-Test & 88 & 100 & 88 & 50 & 88 & 84 & 93 & 77 & 84 \\
\hline $\begin{array}{l}\text { Am. }= \\
\text { Int' }= \\
\text { ON }=8 \\
\text { Off }= \\
\text { no. }=\end{array}$ & $\begin{array}{l}\text { roup taught man } \\
\text { umber of studen }\end{array}$ & Ual ca & & & & & & & & \\
\hline
\end{tabular}

\section{FIGURE 3}

Key Concept Scores of Different Tests:

Percentage of Group Answering Correctly by Concept

Off) the concepts were ranked according to the percent of overall correct answers in decreasing order. The most difficult pretest concepts were LC subject headings, periodicals, and subjects (figure 3 ). On the combined first- and second-level of teaching, corporate author ranked number one (table 4). Table 4 also suggests that in the first- and second-level tests the On group performed better than the Off group for the 3 most difficult concepts. For international students, subjects remained the most difficult concept on the posttest, followed in descending order of difficulty by series, corporate author, LC subject headings, title, and periodical. For American students, on the posttest subject was the most difficult concept as well, followed by LC subject headings, title, corporate author, periodical, and series (figure 3 ).

\section{Opinion Survey Analysis}

Since the results of the opinion survey did not show any evidence of sequence or nationality effects, results on survey ques- tions were pooled. All but 3 of 48 responding students felt that Melvyl was easier to use.

" $82 \%$ of all students considered Melvyl a 'lot of fun' or 'some fun' to use."

Asked about the degree of "fun" in using the system, $82 \%$ of all students considered Melvyl a "lot of fun" or "some fun" to use. No group differences were evident ( $81 \%$ of the American On subgroup, $77 \%$ of the American Off sub group, $80 \%$ of the international On subgroup, and $100 \%$ of the international Off subgroup). In contrast the card catalog was found "OK" to "boring" by $98 \%$ of all students $(100 \%$ of the American On, American Off, and international Off subgroup; $93 \%$ international On subgroup).

The majority $(51 \%)$ of the responding 
students felt that they were "somewhat" in control when using Melvyl, and 55\% had the same response for the card cata$\log$. This pattern was the same for all groups except for students in the American On subgroup. Fifty percent of these students felt in "total control" on Melvyl. Overall $18 \%$ felt unsure when using Melvyl, while $15 \%$ felt unsure when using the card catalog.

Finally, we probed the degree of satisfaction with each system. Overall, $59 \%$ of the responding students were satisfied with Melvyl compared with only $21 \%$ satisfied with the card catalog $(62 \%$ were partially satisfied with the results found using the card catalog). The majority of the American On subgroup (73\%), American Off subgroup (62\%), and international On subgroup (53\%), were very satisfied with Melvyl. When using the card catalog, the majority was only "somewhat satisfied" with its use (64\% of the American On subgroup, $75 \%$ of the American Off subgroup, $47 \%$ of the international On subgroup, and $67 \%$ of the international Off subgroup).

\section{"An important finding of this study is that similar search concepts can be taught equally well on the online cat- alog and on the traditional card cata- log."}

\section{DISCUSSION}

An important finding of this study is that similar search concepts can be taught equally well on the online catalog and on the traditional card catalog (see hypothesis 1 , tables 1 and 2). Since published user studies stress repeatedly the fascination of students with the computerized card catalog, bibliographic instruction librarians can capitalize on this interest and teach search strategies online first, followed by a review of the same concepts in the card catalog.

Due to small sample sizes, the study falls short of concluding that teaching li- brary skills on the online catalog is more effective than teaching on the traditional card catalog (see hypothesis 2, table 1, and figure 3). By looking at the differences between On and Off scores, it appears that there is no advantage to On versus Off teaching. One explanation could be that the Melvyl test was more difficult because the students struggled with two new elements-learning the search techniques and the search concepts. Conceivably this additional degree of difficulty could lower the scores. However, if online teaching is indeed more effective than offline teaching, it would result in higher scores. Consequently, these two factors would cancel each other, resulting in no observable On versus Off differences. Such a possibility although not tested formally is supported by the overwhelming satisfaction with Melvyl training.

The third hypothesis addressed the importance of teaching the systems in a sequence that leads to optimum results in understanding of search concepts. Observation convinced us that students showed increased interest and more active participation during the lecture dealing with online searching, despite the fact that both card catalog and Melvyl lectures used slide presentations to avoid a teaching advantage created by the natural curiosity of students about an interactive system. Teaching concepts on the online catalog followed by teaching concepts on the card catalog leads to better understanding of search concepts than instruction in the reverse order. For American students there was a $6.5 \%$ advantage of being taught online first. For international students, this advantage was even higher, $14.0 \%$. The combined advantage was $8.5 \%$ (table 3 ). The scores for concepts also suggest a sequence effect although this was a trend rather than a statistically significant conclusion. This sequence effect appears to be more evident in the most difficult concepts (table 4).

Regardless of nationality the most difficult concepts to grasp were subject and LC subject headings (figure 3 ). Librarians have long known that author and title searching are immediately understood while LC subject headings are harder to 
grasp. Our data reinforces these findings through statistical observation.

The overwhelming use of the online catalog during the posttest represents an implicit vote for this method of searching. The online catalog was viewed as easier to use and "more fun" than the card catalog. Surprisingly, after a relatively short initiation to online searching, students felt "somewhat" in control on Melvyl (51\%). They had a similar (55\%) response for control of the card catalog, a method presumably used throughout their high school years. Finally, most students were "satisfied" with the results regardless of method. Melvyl received more "very satisfied" comments than the card catalog.

Due to the rigorous admission criteria at the UC-Davis, international students have relatively few language difficulties. Their library knowledge is comparable to that of their American counterparts. During the study, conceptual understanding, sequence effect, and preference for the online system were similar in the American and international subgroups (hypothesis $4)$. The only difference was the use and preference for the card catalog by the international On subgroup. This might be due to cultural differences, previous familiarity with the card catalog, weariness of computers, or simply a "copy cat" effect while being tested.

The small group size and the lack of random selection in the study groups were the major limitations of the study. Small groups created problems of low power and large variability that did not permit conclusive data in hypotheses 2 and 3 . It would take approximately thirty-six students per group (two to three times this study's group size) to have an $80 \%$ chance of detecting (reaching statistical significance) a true difference of ten percentage points from zero for a sequence effect. ${ }^{12}$ Unfortunately for these two hypotheses we could not secure the necessary number of volunteers required by this poststudy analysis to reach a level of statistical significance. Our conclusions are based on the use of a select rather than random group of students. Thus, more research is needed to determine whether these conclusions can be applied to students with library skills and precollege background that is different from that of our study group.

Despite these limitations, several conclusions are suggested by the data:

1. The online catalog is an excellent bibliographic instruction tool that can accommodate search concepts originally taught only for the card catalog.

2. Explaining search strategies with the use of the online catalog, followed by a review of concepts in the card catalog, is the suggested sequence for teaching search concepts.

3. Bibliographic instruction librarians ought to devote special time and attention to the concepts of subject and LC subject headings as methods of accessing the catalog regardless of the type of catalog being taught.

4. The online system is well liked and thus students will use it more often and more effectively than the traditional card catalog.

\section{REFERENCES}

1. David F. Bishop, "The CRL OPAC Study: Analysis of ARL User Response," Information Technology and Libraries 2, no.3:315-21 (1983); Pauline A. Cochrane and Karen Markey, "Catalog Use Studies Since the Introduction of Interactive Catalogs: Impact on Design for Subject Access," Library and Information Science Research 5, no.4:337-63 (1983); Mary Neoel Gouke and Sue Pease, "Title Searches in an Online Catalog and a Card Catalog: A Comparative Study of Patron Success in Two Libraries," The Journal of Academic Librarianship 8, no.3:137-243 (1982); Karen Markey, "Thus Spake the OPAC User," Information Technology and Libraries 2, no.4:381-87 (1983).

2. Sue Pease and M. N. Gouke, "Patterns of Use in an Online Catalog and Card Catalog," College \& Research Libraries 43:279-91 (1982).

3. P. A. Cochrane, "Catalog Use Studies," p.353.

4. Evan Ira Farber, "Catalog Dependency," Library Journal 109, no.3:325-28 (1984). 
5. Mary George and Sharon Hogan, "Teaching Tough Stuff," Research Strategies 1, no.3:136-38 (1983).

6. Evan Ira Farber, "Catalog Dependency," p.326.

7. M. Hills and P. Armitage, "The Two-Period Cross-Over Clinical Trial," British Journal of Clinical Pharmacology 8:7-20 (1979); A. Huitson, "A Review of Cross-Over Trials," The Statistician 31, no.1:71-80 (1983).

8. B. F. Ryan, B. L. Joiner, and T. A. Ryan, Minitab Handbook (Boston: Duxbury Press, 1985); E. L. Lehmann and H. J. D'Abrera, Nonparametrics: Statistical Methods Based on Ranks (San Francisco: Holden-Day Inc., 1975), p.55-120, 269.

9. C. J. Clopper and E. S. Pearson, "The Use of Confidence or Fiducial Limits Illustrated in the Case of the Binomial," Biometrika 26:404-13 (1934).

10. J. L. Fliess, Statistical Methods for Rates and Proportions (New York: John Wiley, 1973), p.72-77.

11. Ibid.

12. Hills and Armitage, "The Two-Period Cross-Over."

\section{APPENDIX A: CROSS-OVER ANALYSIS}

Considering the unequal group sizes, unequal variances, and skewed distributions (table 1), we did not use a cross-over analysis of variance. We expressed the observed score as the sum of the four effects studied including random variation: score (stg) $=u+M+L+S+\mathrm{e}$ (stg), where:

$u \quad=$ Overall mean effect common to all scores

$M \quad=$ Melvyl effect, i.e., the advantage of Melvyl teaching and test; this is a composite of actual teaching mode effects and test difficulty differences. They are not separable with the design used. This effect is zero for card catalog test scores.

$L \quad=$ Learning improvement effect due to second level of teaching; it is zero for a first-level test.

$S$ = Sequence effect, the advantage of having the online first instead of the offline teaching. This can be interpreted as an interaction between teaching mode and level or as carryover or residual effects from the level. It is zero in the first level tests and in the offline tests.

$e(\mathrm{stg})=$ Random deviation of the score from the sum of the above effects due to chance and individual variability. It is assumed that these average to zero within each teaching mode $(t)$ and group $(\mathrm{g})$ combination. They are unique for each student(s), and assumed independent of other student $s$ scores.

Since the $e(\mathrm{stg})$ average to zero for each $(t, g)$, we can express the true mean score as: $u+M$ (if $M$ test) $+L$ (if second test) $+S$ (if On group second test). The true mean score for each $(t, g)$ combination is shown below. Thus the difference of sums across teaching level (Sum) represents the sequence effect. If the difference in mean sums deviates significantly from zero, we may conclude that a sequence effect exists. Note that this is independent of teaching mode, test difficulty, and level of teaching effects.

Level

1

2

Sum
On

$$
\begin{aligned}
& u+M \\
& u+L+S \\
& \hline 2 u+M+L+S \\
& \text { Sum }(\text { On)-Sum }(\text { Off })=S
\end{aligned}
$$

Off

$u$

$\frac{u+M+L}{2 u+M+L}$

Where: On = group taught on Melvyl first. Off = group taught on the card catalog first. 


\section{THE RESOURCE AUTHORITIES.}

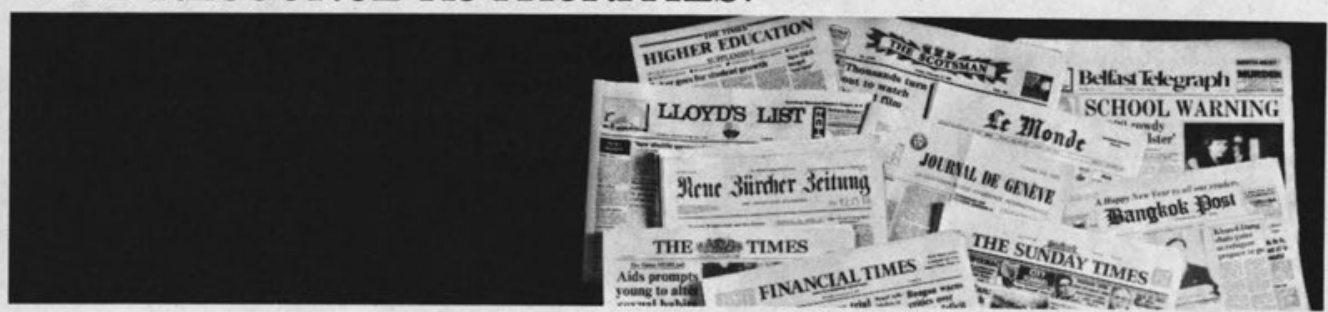

\section{Two hundred historic years of The World's news in microform.}

Over 200 years of factual reporting ... dozens of acclaimed international newspapers like The Times, The Washington Post, Le Monde, Der Spiegel, Asahi Shimbun, The Age, Financial Times, Jewish Chronicle ... all of them available on microfilm from Research Publications.

Imagine the research value of The Times alone: every issue since 1785 - reporting events like the French Revolution, the first flight by the Wright Brothers, and the cultural revolution in China. Scholars, researchers, and the inquisitive public at large have invaluable access to every word. This is probably the most inexhaustible, high-quality collection of international newspapers ever preserved in microform spanning hundreds of years of news publishing, on most of the world's continents, and with editorial content that's limitless in subject matter and interpretation.

For further information, utilize the form below. Or to order current subscriptions and backflles, call Research Publications today at 1-800-REACH-RP (1-800-732-2477). From Connecticut, Alaska and Canada, call collect 203-397-2600.

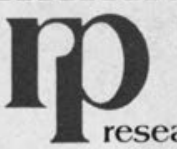

12 Lunar Drive/Drawer $A B$ Woodbridge, CT 06525 Woodbridge, Toll-free: 1-800-REACH TWX: 710-465-6345 Transcripts and Indexes

$\square$ Journals in Microform

$\square$ Research Collections in Microform $\square$ U.S. and Interna tional Patent Documentation $\square$ Patent Search and Awareness Services

$\square$ Reference Boolus
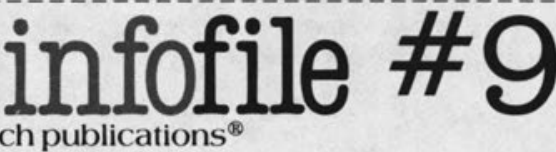

CRL

\section{International Newspapers}

$\square$ Please send me your brochures.

$\square$ Have a representative call me.

\begin{tabular}{lll}
\hline Name & Tillo & \\
\hline Inetitution & & \\
\hline Addrose & & \\
\hline City & State & 2ip code \\
\hline Phong
\end{tabular}

For further information, or to place your order directly, call 1-800-REACH-RP (1-800-732-2477).

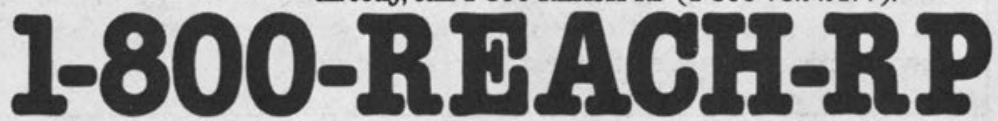

